\title{
Effect of Halabjah Earthquake on Al-Wand Earth Dam: Numerical Analysis
}

\author{
Intisar H. Abbas ${ }^{1, a}$ and Maysam Th. Al-hadidi ${ }^{2, b}$ \\ ${ }^{1}$ Civil Engineering Department, University of Baghdad, Baghdad, Iraq. \\ ${ }^{2}$ Water Resources Engineering Department, University of Baghdad, Baghdad, Iraq. \\ ai.alwaily1901m@,coeng.uobaghdad.edu.iq, bMays.thamer@,coeng.uobaghdad.edu.iq
}

\begin{abstract}
The Halabja earthquake occurred on 12/11/2017 in Iraq, with a magnitude of $7.3 \mathrm{Mw}$, which happened in the Iraqi-Iranian borders. This earthquake killed and injured many people in the Kurdish region in the north of the country. There is no natural disaster more dangerous than earthquake, especially it occurs without warning, great attention must be paid to the impact of earthquakes on the soil and preparing for a wave of earthquakes. Numerical modeling using specific elements is considered a powerful tool to investigate the required behavior of structures in Geotechnical engineering, and the main objective of this is to assess the response of the Al-Wand dam to the Halabja earthquake, as this dam is located in an area that has been subjected to seismic activity recently. The modeling was done through the Geo-studio program, where the seepage was analyzed during the Al-wand dam using the Seep/w program. It was verified that the dam was safe against seepage failure and then moved to the QUAKE/W (a subprogram of GEOSTUDIO, which is used for liquefaction modeling of earthquakes and dynamic loading and determines the movement and increased pressures of pore water that arise due to earthquake vibration or sudden shock loads). The program was used to analyze the effect of the earthquake on the porewater pressure, effective stresses, and displacements. Also, it is not clear that the significant impact the earthquake has on these values. Finally, the Slope/w program was used to analyze the stability of the dam and to calculate the safety factor of the dam in two ways, and the results of the analysis show that the dam is considered safe under the influence of the tremor.
\end{abstract}

Keywords: Halabja earthquake; QUAKE/W; Al-wand earth dam; seismic.

\section{Introduction}

An earthquake is a vibration of the earth's surface resulting from the sudden release of energy in its crust and upper mantle, a natural phenomenon that occurs unexpectedly due to the breakage of layers of underground rocks energy causes movement and vibration of the earth. Earthquakes are either so weak that they cannot be felt or may reach enough violence to destroy Entire cities. Seismic activity is the activity of a region that is the frequency, type, and size of the earthquakes that have been exposed to it over some time, and dams act differently in response to earthquake events depending on their strength [1]. An earthquake may threaten the stability of the dam body or cause complete damage or deformation on the bridge, and during that effective pressure occurs between the soil particles from the lower dam and the water, the pressure increases in the soil pores, and the change from a solid-state to a liquid state occurs. Liquefaction can lead to failure of the source or the foundations of the dam bridges [2].

In the recent period, Iraq was subjected to unprecedented seismic activity, especially near the border with Iran, so the need to study the impact of seismic activity on Iraq and reassess the seismic risk in this region, as a magnitude 7.3 earthquake occurred between Iraq and Iran [3]. Therefore, the entire Iraqi-Iranian border was affected, but the epicenter was in Iran near Izgil. In Kermanshah, the consequences of the earthquake were more pronounced in the surrounding areas. The epicenter area and fault lines. Different sizes cause different rupture lengths for error; an M 5+ earthquake might cause fault slip a few kilometers in the process. The length could extend to $400 \mathrm{~km}$ if the magnitude increased to M8. It was the epicenter, it is located between two active fault lines at Zagros Mountain Front Volt (M.F.F.) of 1368 km long The H.Z.F. High Zagros Fault (H.Z.F.), which has a fault length of $1,375 \mathrm{~km}$, is where the M.F.F. movement caused earthquake [4], and the study will include an 
analysis of the response of the dam Al-wand, which is located in Diyala, which has been exposed to continuous seismic activity in recent times [5]. Al-wand dam was established on the Al-wand River in the southeast of the city of Khanaqin, and the purpose of its establishment was to irrigate the agricultural lands as well as protect the neighboring areas from flooding. The geology of the area helps him in this. The topography helped to prepare the dam with a certain height and length [6]. The dam's stability against seepage failure is studied, the response of the dam to earthquakes was analyzed using the QUAKE/W program, a subprogram of geo-studio, because of the importance of the dam in preserving the area from floods and water storage. After that, the safety factor will be calculated after the occurrence of the earthquake and compared with what was mentioned in the standard to identify the extent of the safety of the Al-wand dam under the influence of the earthquake.

\section{Description of Al-Wand Earth Dam}

The Al-wand Dam is located in Diyala Governorate. The Al-wand Dam is located in the Al-wand River, $7 \mathrm{~km}$ southeast of Khanaqin, $6 \mathrm{~km}$ from the Iraqi-Iranian borders, and the purpose of the construction of the dam was to use water for irrigation purposes. Its location was chosen based on the results of geological investigations and topographic surveys and the availability of the necessary materials for its construction. Approval of its establishment as an earthen embankment with a clay core surrounded by a filter material and filled with gravel and sand on its sides. Table 1 includes the general specifications for Al-wand Dam.

Table 1. Properties of Al-Wand dam [4].

\begin{tabular}{|l|c|c|c|}
\hline Property & Value & Property & Value \\
\hline Dam length & $2800 \mathrm{~m}$ & Work burial & $793000 \mathrm{~m}^{3}$ \\
\hline Dam high & $24 \mathrm{~m}$ & Maximum flood discharge & $1500 \mathrm{~m}^{3} / \mathrm{sec}$ \\
\hline Spillway length & $210 \mathrm{~m}$ & Elevation of maximum water level (M.W.L) & $217.25 \mathrm{~m}$ \\
\hline Width of the top of the dam & $8 \mathrm{~m}$ & Elevation of Normal water level (N.W.L) & $215 \mathrm{~m}$ \\
\hline Total storage capacity & $51830000 \mathrm{~m}^{3}$ & Elevation of Dam summit level & $219 \mathrm{~m}$ \\
\hline Live storage & $37820000 \mathrm{~m}^{3}$ & Elevation of the lowest point at the bottom & $195 \mathrm{~m}$ \\
\hline
\end{tabular}

Al-Wand dam consists of several layers, and these layers are of different thicknesses, where the most significant value is at the base and decreases towards the top of the dam. Figure1 shows the layers of the material that make up the dam.

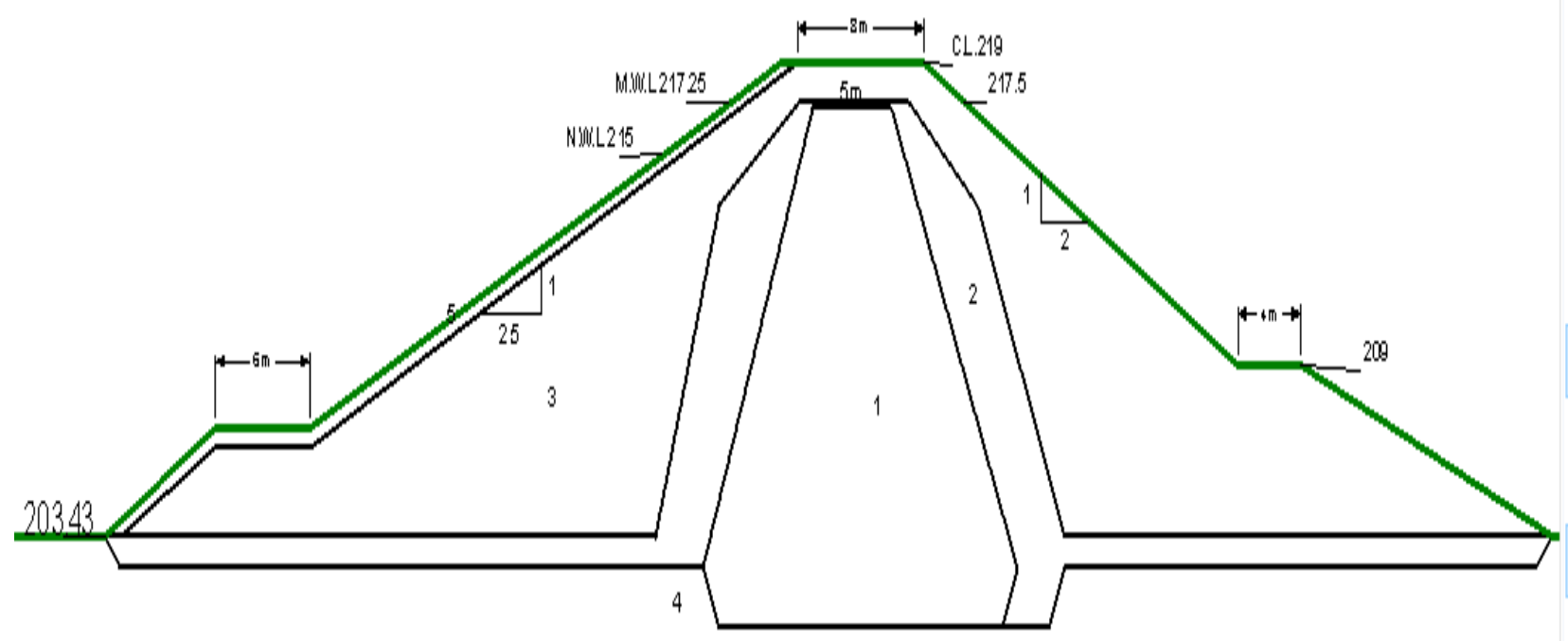

1-Clay core, 2-filter, 3-gravel and sand fill for U/S and D/S 4-Foundation, 5-U/S Riprap (0.3 m thickness)

Figure 1. Cross-section of Al-Wand earth dam (scale 1:500). 


\section{Analysis of Seepage}

Seepage analysis during the water level before the effect of the earthquake by using SEEP/W program can draw as shown below, which illustrates the path. (Phreatic line through the dam [7]).

Velocity Vectors. The seepage velocity analyzed as shown in the figure, and the results of the maximum seepage velocity in the core zone is $2.5 \times 10^{-9} \mathrm{~m} / \mathrm{sec}$, and the safety of the dam is acceptable. Seepage line passes through the filter shows that, Hydraulic conductivity $4.8 \times 10^{-9} \mathrm{~m} / \mathrm{sec}$ More than the seepage velocity of $2.5 \times 10^{-9} \mathrm{~m} / \mathrm{sec}$. That is mean the core can pass the water, which is safe against piping failure.

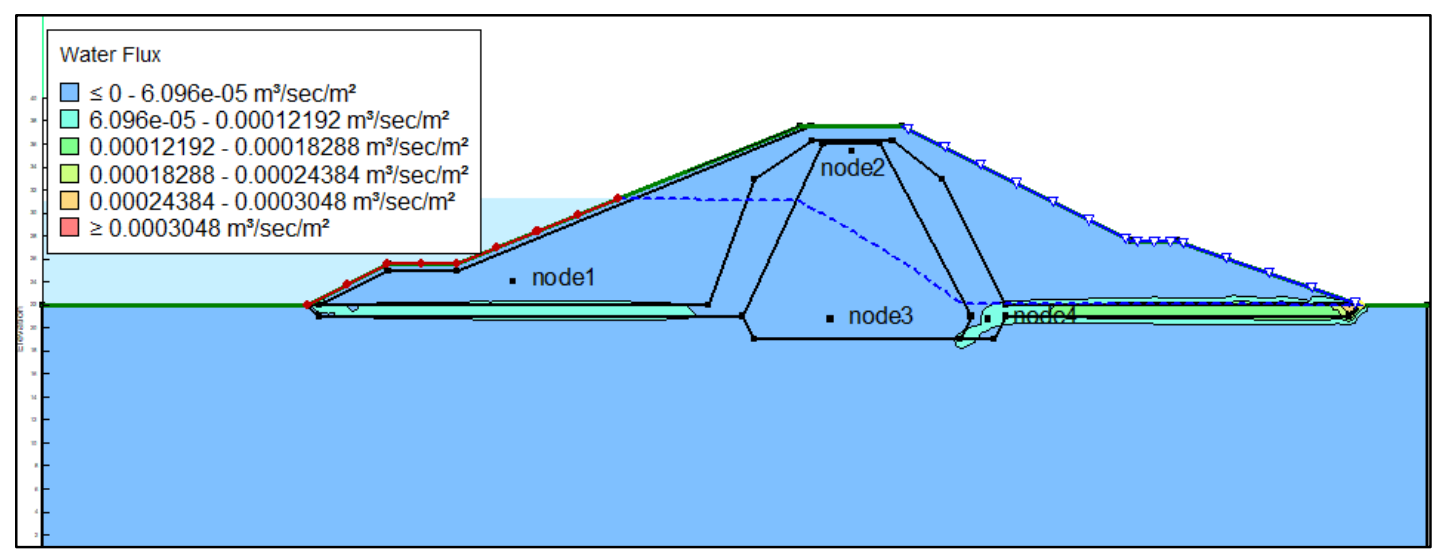

Figure 2. Water flux.

Hydraulic Gradients. From Figure 3, it found that the maximum exit hydraulic gradient $\left(i_{\mathrm{e}}\right)$ is $(0.2)$ so the factor of safety against uplift equal to $\left(i_{c} / i_{\mathrm{e}}\right)=(1 / 0.2)=5$. In the $(U S B R, 2014)$ limits, the factor of safety against uplift should not less than 2, so the dam's safety is acceptable. So, we can notice that Al-Wand earth dam is safe against failure in seepage at a steady state according to hydraulic safety criteria of USBR [8].

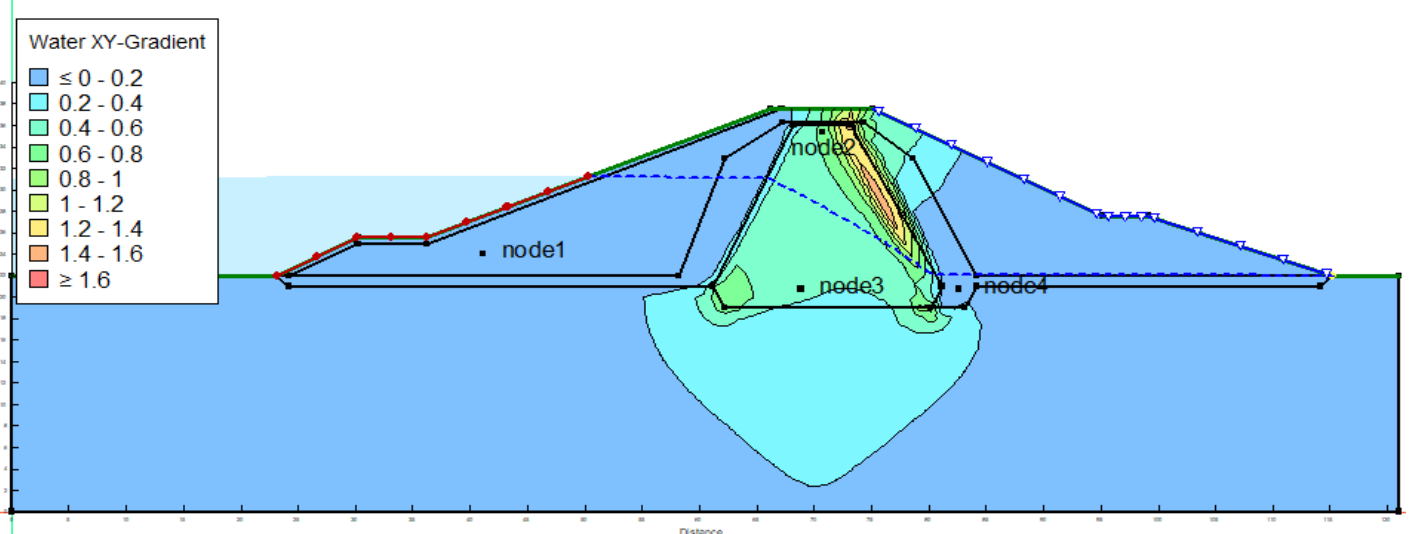

Figure 3. Water X.Y. gradient.

\section{Dynamic Analysis of Al-Wand Dam}

Analyzing the seepage during and under the body of the dam was conducted using SEEP/W program. After the introduction of the properties of the materials of the dam and the introduction of the boundary condition with total head equals to the water level in the reservoir, and the downstream boundary nodes are designated with total flux equals to zero. It calculates the pore water pressure and making sure that the results that emerged are comparable to the real results. Moved to the initial state and then the dynamic state to know the effect of earthquakes using the QUAKE/W program, the characteristics of the soil composing the dam were entered, which are shown in Table 4, and then the 
boundary condition was entered, which is the restriction of movement. In the directions, $\mathrm{x}, \mathrm{y}$ at the bottom of the dam and the vertical movement is restricted in the dam's sides.

Table 4. Materials properties of Al-Wand dam [9].

\begin{tabular}{|c|c|c|c|c|}
\hline Material & $\begin{array}{c}\text { Permeability } \\
\mathbf{m} / \mathbf{s e c}\end{array}$ & $\begin{array}{c}\text { Unit weight } \\
\mathbf{k N} / \mathbf{m}^{\mathbf{3}}\end{array}$ & $\begin{array}{c}\mathbf{c} \\
\mathbf{N} / \mathbf{m}^{\mathbf{2}}\end{array}$ & $\begin{array}{c}\boldsymbol{\varphi} \\
\text { degree }\end{array}$ \\
\hline Core & $4.8 \times 10^{-9}$ & 18 & 210 & 10 \\
\hline Shell & 0.001 & 18 & 0 & 25 \\
\hline Fine filter & 0.07 & 18 & 0 & 30 \\
\hline Coarse filter & 0.11 & 18 & 0 & 30 \\
\hline Upper layer & $8 \times 10^{-5}$ & 20 & 30 & 30 \\
\hline
\end{tabular}

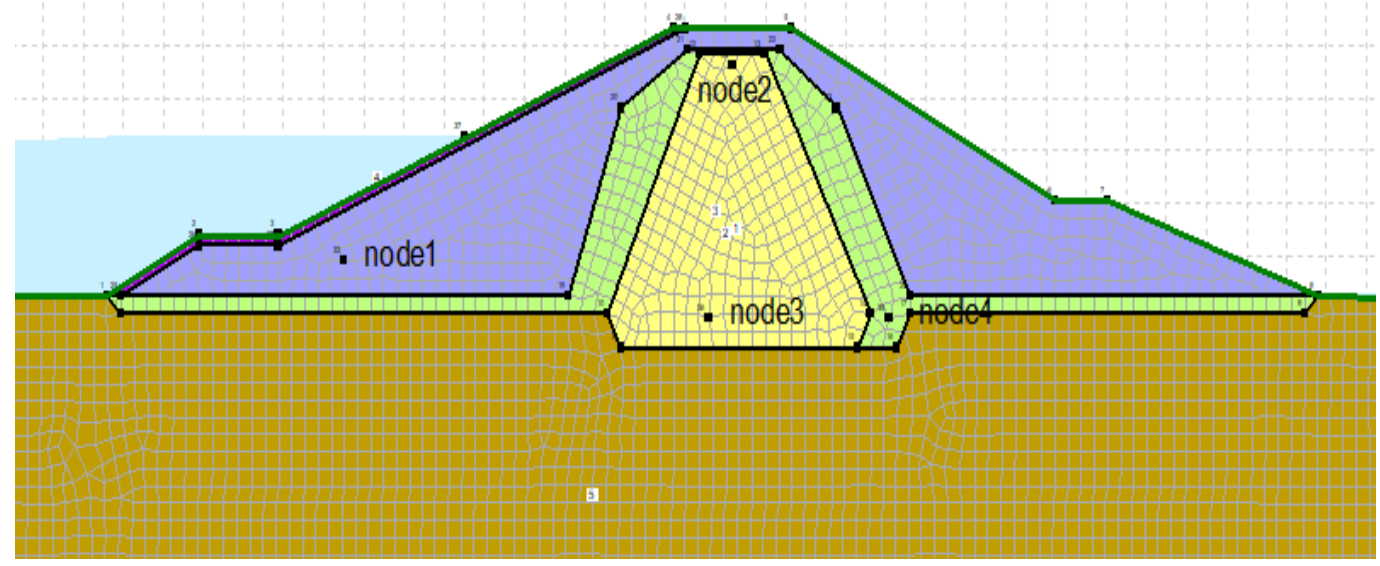

Figure 4. The element mesh and the selected nodes of Al-Wand dam.

\section{Earthquake Record}

Halabjah earthquake, which happened on 12/11/2017, with a magnitude of $7.3 \mathrm{Mw}$ and duration of $205 \mathrm{sec}$ is shown in Figure 5, and the water level in the reservoir is $9.24 \mathrm{~m}$.

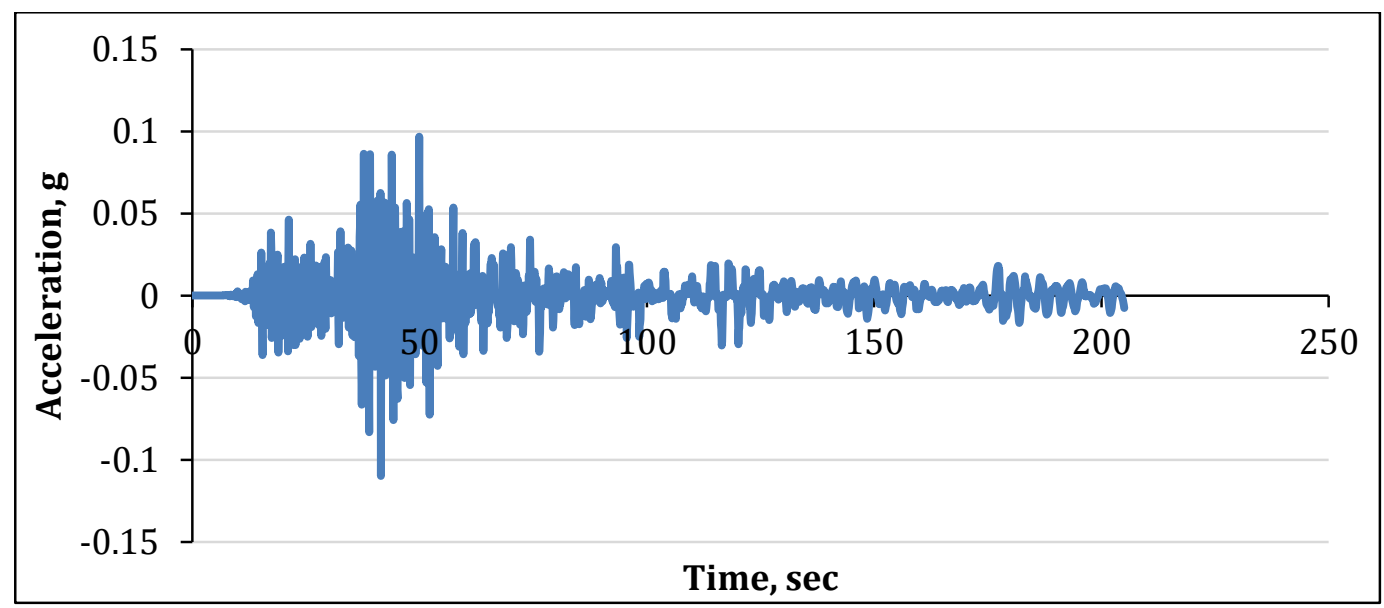

Figure 5. Acceleration - time history record for Halabjah earthquake.

\section{Results and Discussion}

Porewater Pressure. The effect of an earthquake on the pore water pressure of Al-Wand earth dam is shown in Figure 6. It is noted that the change in pore water pressure is very slight under the influence of earthquakes. 

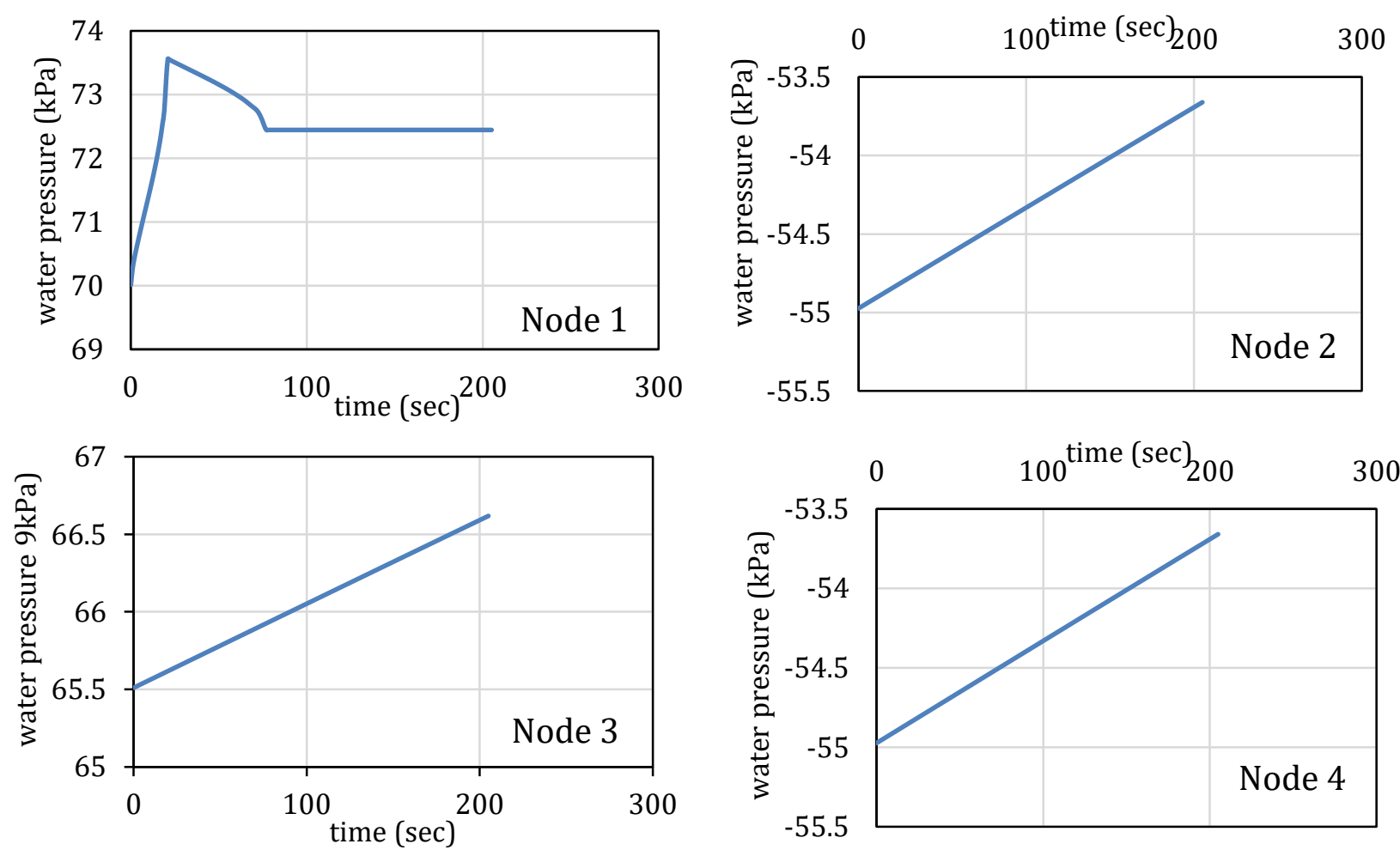

Figure 6. Porewater pressure $(\mathrm{kPa})$-time $(\mathrm{sec})$ at nodes 1,2,3 and 4 during the earthquake.

Displacement. The Y-Displacement -time at nodes 1,2,3,4 shown in Figure 7. The maximum Ydisplacement at node 2 is equal to $0.009 \mathrm{~m}$, and the minimum Y-displacement at node 3, and at all nodes, the maximum displacement occurred at the time $(80-100 \mathrm{sec})$.

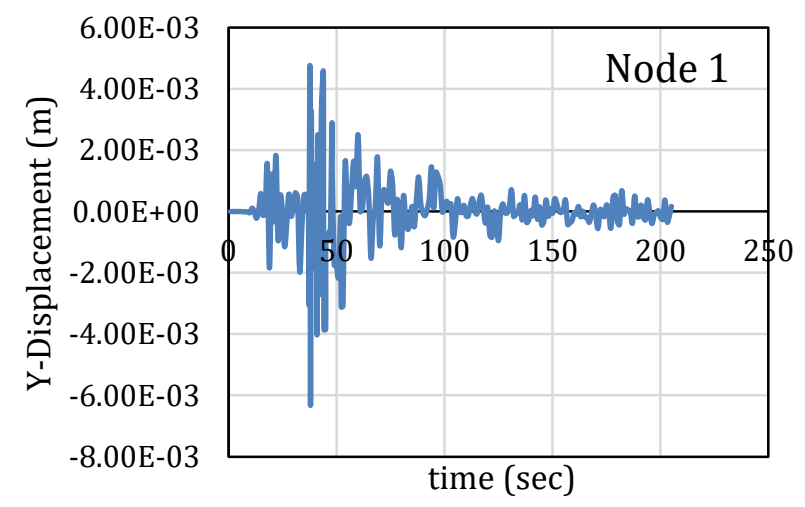

a) Node1

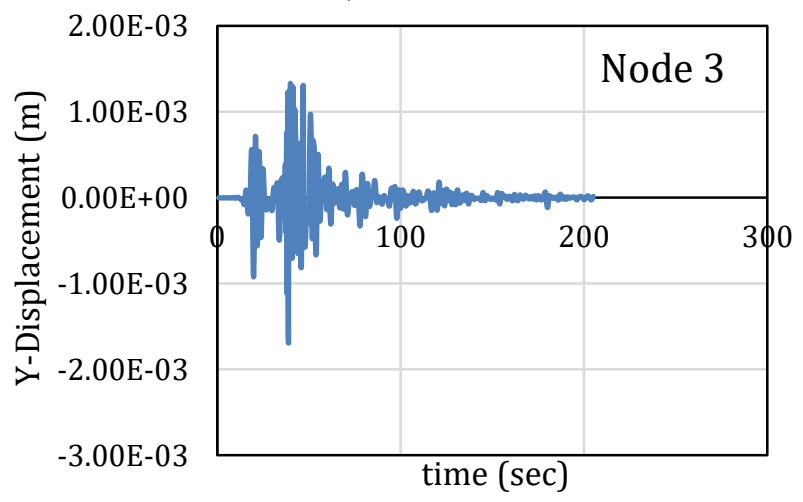

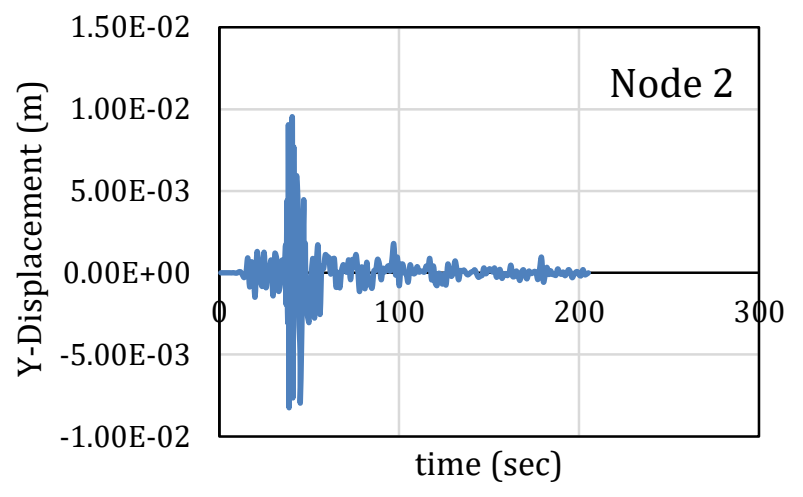

b) Node2

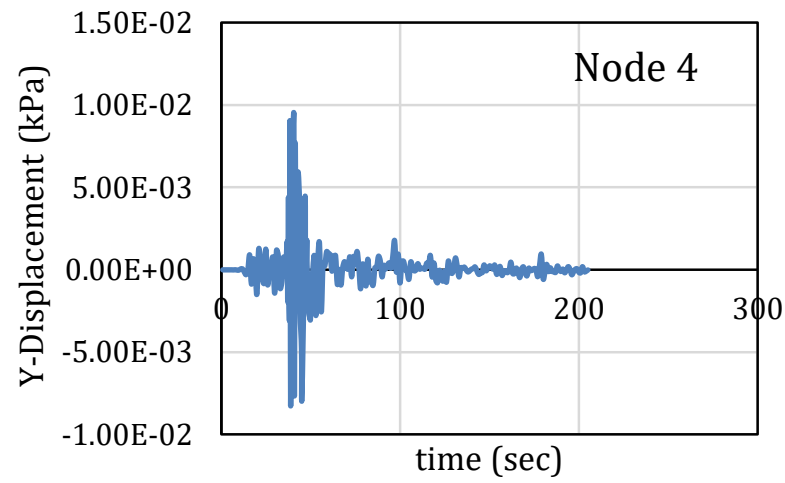

Figure 7. Y-displacement (m)-time (sec) at nodes 1, 2, 3, and 4 during Halabjah earthquake. 
Effective Stress. The X-effective stress with time is shown in Figure 8. The X-effective stress with time does not change a lot during the earthquake, and the maximum $\mathrm{x}$-effective stress at node 2 and the minimum is at node 1.
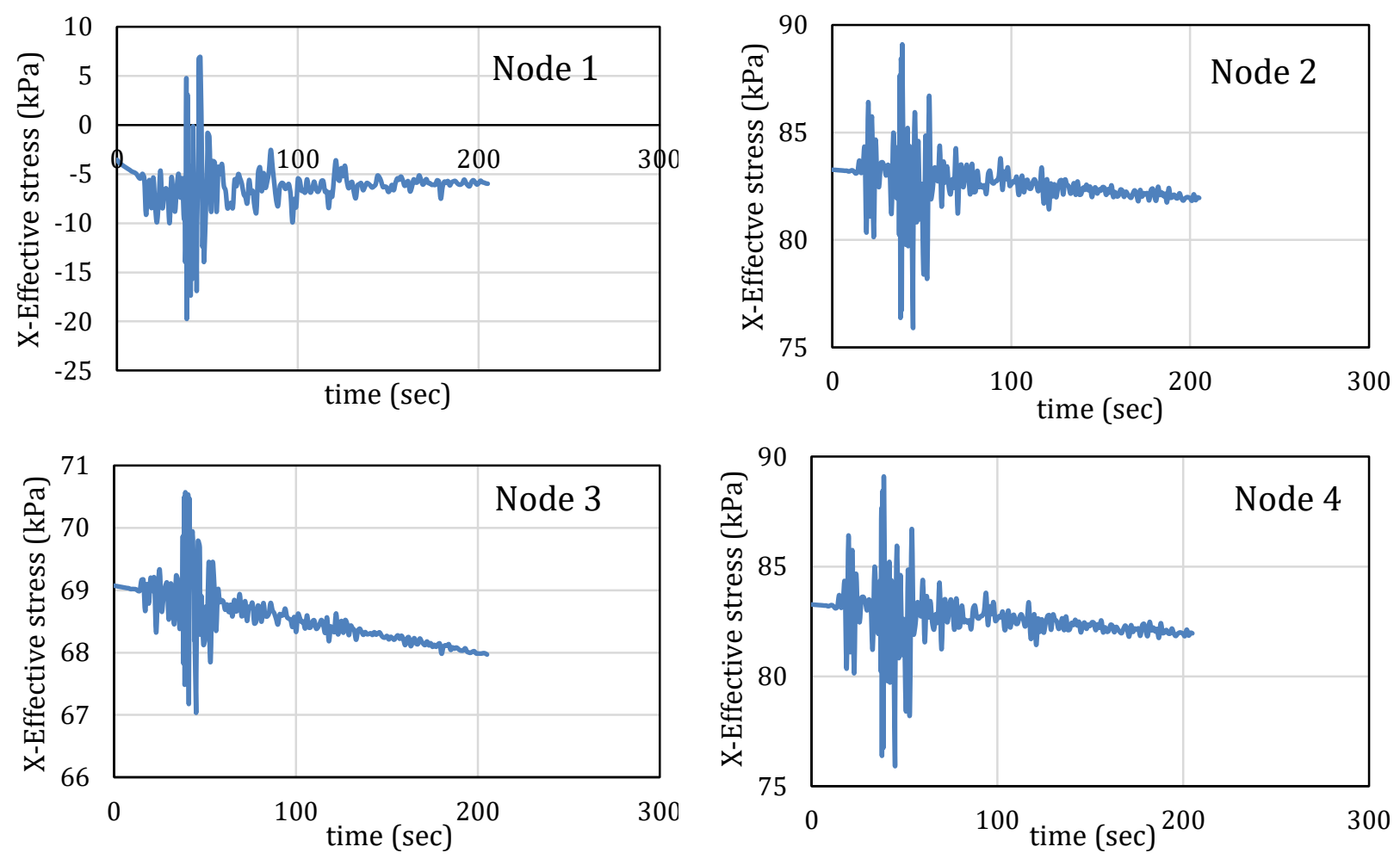

Figure 8. X-Effective stress -time at nodes 1, 2, 3, and 4.

The y-effective stress with time at nodes1, 2, 3, and 4 during Halabja earthquake is also not changed a lot with time, and the maximum y-effective stress at node 4 and the minimum is at node 1.
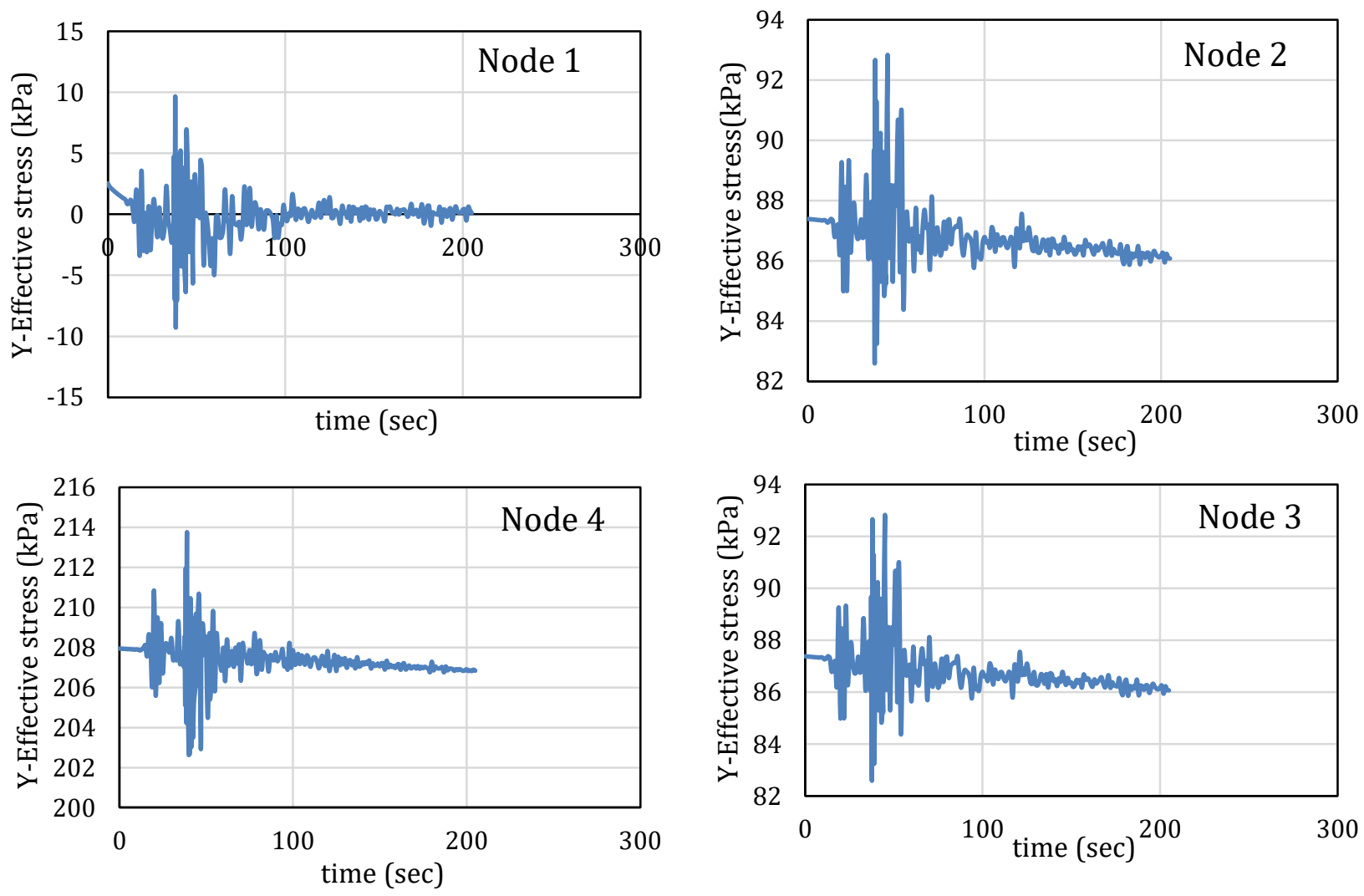

Figure 9. Y-effective stress -time at nodes 1, 2, 3, and 4. 
Analysis of Stability of the Slope by SLOPE/W. The SLOPE/W program is used to identify the slope stability and verify by different analysis methods. Accordingly, an analysis is performed in terms of effectiveness and pressures for each case. The critical slip surface analysis gives the minimum safety $[10,11]$. Then the material properties are entered in the paragraph for the slope/w program, and then the range of the slip surface is entered, where we will use the first case for the upstream and second case for the downstream, then analyze the dam and identify the results using two methods. Figure 10 shows the factor of safety according to the four methods.

The lowest value of the safety factor can be observed before the effect of the earthquake. Depending on the results of the analysis from SEEP/W program, the minimum value of the factor of safety for upstream is 3.119 , and for the downstream is 3.072. Table 5 shows the resulting values for which will be compared with the value mentioned in the standard, which is equal to 1.2 , so the safety factor of the dam during the earthquake more than the safe standard. The factor of safety that was analyzed by Janbu method decreases to a minimum. The factor of safety in upstream and downstream of the dam is 2.979 and 2.972 respectively, that mean the factor of safety reduced about $4.5 \%$ and 3.3 $\%$ in upstream and downstream, respectively.

Table 5. Summary results of a minimum factor of safety for stability slope analysis of Al-Wand dam.

\begin{tabular}{|c|c|c|}
\hline Analysis method & Upstream slope & Downstream slope \\
\hline BDS, 1994 & $1.0-1.2$ & $1.0-1.2$ \\
USACE, 2003 & $1.0-1.2$ & $1.0-1.2$ \\
Janbu & 2.979 & 2.971 \\
\hline spencer & 5.120 & 2.838 \\
\hline
\end{tabular}
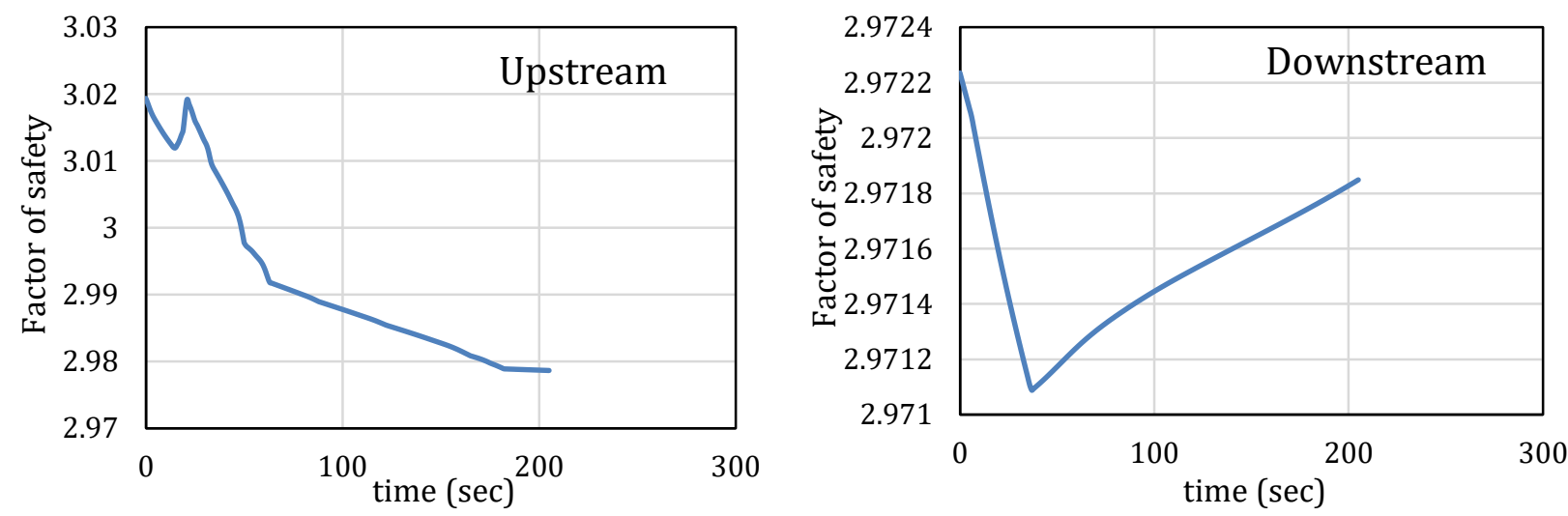

a) Factor of safety of Al-wand dam using Janbu method
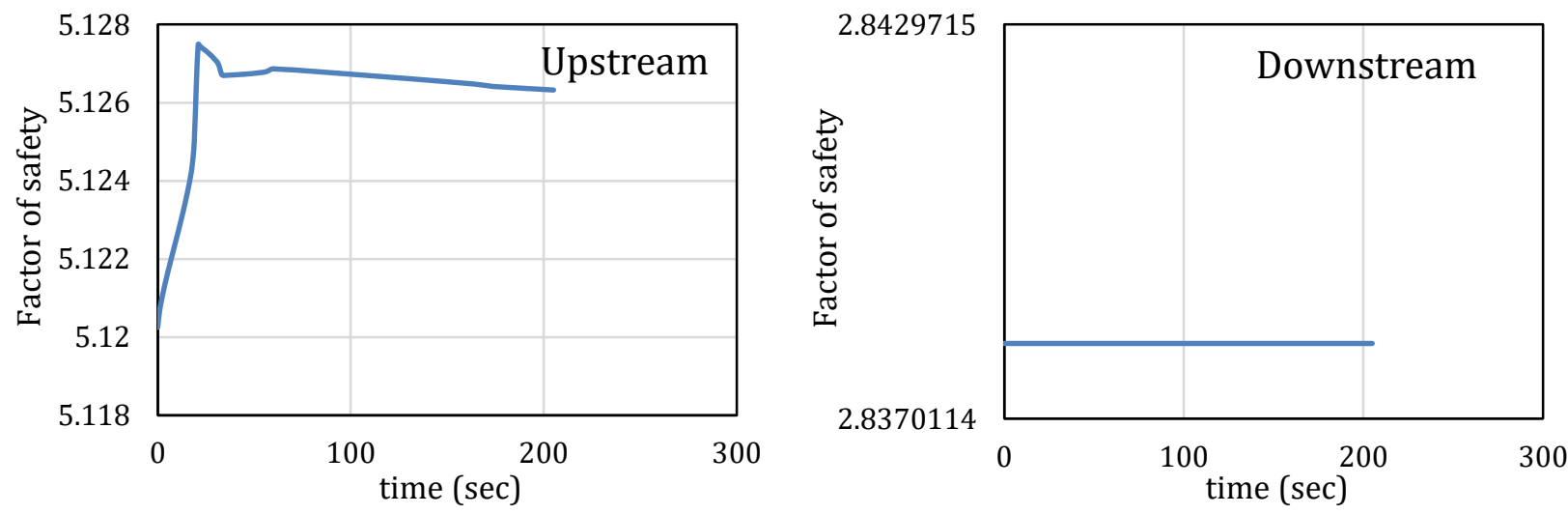

b) Factor of safety of Al-wand dam using Spencer method

Figure 10. Factors of the safety of the downstream and upstream of Al-Wand dam after the effect of the earthquake using different methods. 


\section{Conclusions}

1) When we made a seepage analysis for Al-Wand dam, we conclude that the dam is safe against seepage (piping) failure, uplift.

2) The pressure of the pore water increases a little unnoticed under the influence of the Halabjah earthquake.

3) When comparing the Y-displacement results from the obtained figures and comparing them with the permissible displacement, the resulting values are less than the maximum settlement allows $(24 \mathrm{~cm})$, and thus the dam is safe in this respect.

4) The minimum values of safety factor that calculation charts for analyzing the dam's stability by different methods show that the safety factor values obtained when compared with the standard are within the permissible rate. Therefore, the dam can be considered safe against failure during Halabjah earthquake.

5) The safety factor calculation charts for analyzing the stability of the dam by different methods show that the safety factor values obtained, which the minimum value of the factor of safety obtained from Janbu method, which is equal to 2.972 when compared with the standard, are more than the permissible rate (1-1.2). Therefore, the dam can be considered safe against failure during Halabjah earthquake.

6) The analysis of the slopes at the time of the earthquakes shows decreases of safety factor in the upstream and downstream of the dam, about $4.5 \%$ and $3.3 \%$ in respectively.

\section{References}

[1] Al-Nedawi, N.M., 2020. Finite Element Analysis of Seepage for Hemrin Earth Dam Using GeoStudio Software. Diyala Journal of Engineering Sciences, 13(3), pp.66-76.

[2] Izzeddin, H., Malek, H., and Homan, A., 2016. Analytical study of earthquakes effect on embankment dams by finite element method case study: Al Basel dam/Tartous.

[3] Al-Taie, A.J. and Albusoda, B.S., 2019. Earthquake hazard on Iraqi soil: Halabjah earthquake as a case study. Geodesy and Geodynamics, 10(3), pp.196-204.

[4] Onur, T., Gok, R., Abdulnaby, W., Shakir, A.M., Mahdi, H., Numan, N., Al-Shukri, H., Chlaib, H.K., Ameen, T.H. and Abd, N.A., 2016. Probabilistic seismic hazard assessment for Iraq (No. LLNL-TR-691152). Lawrence Livermore National Lab. (LLNL), Livermore, CA (United States).

[5] Abdulnaby, W., Al-Mohmed, R. and Mahdi, M., 2016. Seismicity and recent stress regime of Diyala City, Iraq-Iran border. Modeling Earth Systems and Environment, 2(3), pp.1-8.

[6] Center of Designs and Studies, 2020. Al-Wand dam. Unpublished Report, Ministry of Water Resources, Iraq.

[7] Jassama, M.G. and Abdulrazzaqb, S.S., 2020. Analysis of seepage through Al-Wand Dam by using SEEP/W Model. Anbar Journal of Engineering Sciences, 8(2).

[8] Mahmoud, A.I., Hussein, H.A. and Khaled, Z.S., 2021, February. Numerical Model of Seepage Analysis and Slope Stability for Horan Dam H4 in Iraq. In I.O.P. Conference Series: Materials Science and Engineering (Vol. 1076, No. 1, p. 012089). I.O.P. Publishing.

[9] Fattah, Mohammed Y., Hasan A. Omran, and Mohammed A. Hassan. Flow and stability of AlWand earth dam during rapid drawdown of water in reservoir. Acta Montanistica Slovaca 22, no. 1 (2017).

[10] Arshad, I., Babar, M.M. and Javed, N., 2017. Numerical Analysis of Seepage and Slope Stability in an Earthen Dam by Using Geo-Slope Software. P.S.M. Biological Research, 2(1), pp.13-20.

[11] Abbas, J.M. and Mutiny, Z.A., 2018. Slope Stability Analysis for Earth Dams Using (GeoSlope/W). Diyala Journal of Engineering Sciences, 11(1), pp.70-81.

[12] Williamson, T., 2016. British Dam Society strategy: the future of the B.D.S. Dams and Reservoirs, 26(2), pp.59-61.

[13] G Deraa, M., H Jalut, Q. and M Abbas, J., 2019. Numerical Modeling to the Dynamic Response of Mindali Earth Dam. International Journal of Civil Engineering and Technology, 10(8). 